\title{
[gw22-e0505] THE EFFECT OF AEROBIC EXERCISE ON BLOOD PRESSURE AND LIPID METABOLISM IN OBESE ADOLESCENTS
}

Yang Dongsheng', Li Haipeng ${ }^{2}$ Fitness and Health Research Institute, Zhejiang Technology University, Hangzhou, China; ${ }^{2}$ School of Kinesiology, Shanghai University Of Sport, Shanghai, China

10.1136/heartjnl-2011-300867.313

Objectives Obesity is a major risk factor for type 2 diabetes, insulin resistance, dyslipidemia, hypertension and many other chronic diseases. Aerobic exercise has been shown to be beneficial to lipid metabolism and cardiovascular fitness. Yet the related mechanisms of this association are poorly understood in adolescents. The purpose of this study is to investigate the effects of aerobic exercise on blood pressure, lipid metabolism and the relation of BMI and both blood pressure and lipid metabolism.

Methods Eight obese adolescents (four boys and four girls, $13.88 \pm 1.96$ years, BMI is $33.27 \pm 5.63$ ), from ZHUOER closed weight loss summer camp of Hang Zhou, performed aerobic exercise five times per week over 6 weeks period at an intensity of approximately $75 \%$ of HRmax. All subjects took standard meals and routine of the day. The content of LDL, HDL, total cholesterol and blood pressure were measured before and after the 6 week exercise program.

Results After 6 weeks of aerobic exercise, BMI went from $33.27 \pm 5.63$ to $30.07 \pm 5.30(p<0.01)$, the content of HDL went from $1.39 \pm 0.15$ to $1.27 \pm 0.16(p>0.05)$, the content of LDL went from $2.86 \pm 0.44$ to $2.12 \pm 0.26(\mathrm{p}<0.01)$, the total cholesterol level went from $5.08 \pm 0.70 \mathrm{mmol} / \mathrm{l}$ to $4.10 \pm 0.36 \mathrm{mmol} / 1$ $(\mathrm{p}<0.05)$, the systolic blood pressure went from $119.50 \pm 8.40$ $\mathrm{mm} \mathrm{Hg}$ to $108.0 \pm 18.46 \mathrm{~mm} \mathrm{Hg}(\mathrm{p}<0.01)$, the diastolic blood pressure went from $79.75 \pm 12.76 \mathrm{~mm} \mathrm{Hg}$ to $65.75 \pm 12.12 \mathrm{~mm} \mathrm{Hg}$ $(\mathrm{p}<0.05)$. The positive correlations were found in BMI and systolic blood pressure $(\mathrm{r}=0.769, \mathrm{p}<0.01), \mathrm{BMI}$ and diastolic blood pressure $(r=0.441, p<0.01)$.

Conclusion Six weeks aerobic exercises can significantly decrease BMI, plasma LDL level, total cholesterol level, the systolic blood pressure and the diastolic blood pressure in obese adolescents, but the plasma HDL level did not show significant changes. Aerobic exercise improves blood pressure and is associated with reduced BMI in obese adolescents. 